\title{
Effect of $\mathrm{NbB}_{2}$ Addition on the Microstructure and Mechanical Properties of Mechanically Alloyed Al-12.6Si Alloys
}

\author{
Emre Tekoğlu' ${ }^{1}$, Sıddıka Mertdinç${ }^{1}$, Hasan Gökçe ${ }^{2}$, Duygu Ağaoğulları ${ }^{1}$, M. Lütfi ÖVEÇOĞLU ${ }^{1}$ \\ ${ }^{1}$ Istanbul Technical University, Chemical and Metallurgical Engineering Faculty, Metallurgical and Materials Engineering \\ Department, Particulate Materials Laboratories (PML), 34469, Maslak, Istanbul, Turkey \\ tekoglue@itu.edu.tr; mertdinc@itu.edu.tr; bozkurtdu@itu.edu.tr; ovecoglu@itu.edu.tr \\ ${ }^{2}$ Prof. Dr. Adnan Tekin Materials Science and Production Technologies Applied Research Center (ATARC), \\ Istanbul Technical University, 34469, Maslak, Istanbul Turkey \\ gokceh@itu.edu.tr
}

\begin{abstract}
This study reports the effect of $\mathrm{NbB}_{2}$ particles on the Al-12.6 wt.\% Si matrix powders and composites in regard of physical, microstructural and mechanical properties. In order to obtain hybrid powders, Al-12.6 wt.\% Si- 2 wt.\% NbB 2 blends were mechanically alloyed (MA'd) for various durations (1, 4 and $8 \mathrm{~h}$ ) in a Spex ${ }^{\mathrm{TM}}$ Mixer/Mill using hardened steel vial/balls with a 7/1 ball-to-powder weight ratio. A hydraulic press with a uniaxial pressure of $450 \mathrm{MPa}$ was used for the compaction of the as-blended/MA'd powders. Green compacts were sintered at $570^{\circ} \mathrm{C}$ for $2 \mathrm{~h}$ under Ar gas atmosphere. X-ray diffractometry (XRD) and scanning electron microscopy/energy dispersive spectroscopy (SEM/EDS) techniques were utilized for the microstructural characterization of the as-blended/MA'd powders and the sintered composites. Differential scanning calorimetry (DSC) analyses were also conducted on the powder products. Sintered samples were characterized by density and Vickers microhardness measurements and sliding wear tests. With increasing MA time, mechanical improvement in composite properties was observed. Reinforcing particles had positive effect on the mechanical properties of the matrix: Al-12.6 wt.\% Si-2 wt.\% $\mathrm{NbB}_{2} \mathrm{MA}^{\prime} d$ for 4 h showed higher microhardness value (158.50 $\left.\pm 10.02 \mathrm{MPa}\right)$ and lower wear volume loss $\left(0.161 \mathrm{~mm}^{3}\right)$ than those of Al-12.6 wt.\% Si matrix MA'd for $4 \mathrm{~h}$. Al-12.6 wt.\% Si matrix MA'd for 4 h showed microhardness value $(146.70 \pm 8.81 \mathrm{MPa})$ and wear volume loss $\left(0.194 \mathrm{~mm}^{3}\right)$.
\end{abstract}

Keywords: Al-Si matrix composites, $\mathrm{NbB}_{2}$ Reinforcing particles, Mechanical alloying, Pressureless sintering.

\section{Introduction}

Al-Si matrix composites have been mostly used in aerospace technologies in which utilization of low-density materials is a significant requirement [1]. These materials also exhibit high corrosion resistance, high ductility, high strength and high wear resistance [2-3].

Al-Si matrix composites have been mostly produced by casting and powder metallurgy techniques [3]. However, to reach a homogeneous distribution throughout the composite structure is very hard by traditional casting methods. Besides, sub-micron reinforcement particles tend to agglomerate in the molten metal during the production of metal matrix composites $[4,5]$.

It is very important to homogeneously disperse the reinforcements in the metal matrix with no agglomeration [6]. Otherwise, an inhomogeneous matrix will not perform desired properties due to segregation. The required energy for the dispersion of the elemental powders within each other can be provided by the effect of high mechanical energy [7]. Mechanical alloying (MA) which is a solid-state processing technique based on welding, fracturing and rewelding of the particles is drived by high energy ball milling [8]. Particle sizes dramatically decrease and particle size distribution becomes narrower with increasing MA time [8]. Moreover, powders are exposed to high deformation which causes deformation strengthening [9].

Up to now, oxides $\left(\mathrm{Y}_{2} \mathrm{O}_{3}, \mathrm{La}_{2} \mathrm{O}_{3}, \mathrm{Al}_{2} \mathrm{O}_{3}, \mathrm{SiO}_{2}\right)$, borides $\left(\mathrm{TiB}_{2}, \mathrm{ZrB}_{2}\right)$, carbides ( $\left.\mathrm{SiC}, \mathrm{TiC}, \mathrm{ZrC}\right)$ and nitrides $\left(\mathrm{AlN}, \mathrm{Si}_{3} \mathrm{~N}_{4}\right)$ have been added as reinforcements into the metal matrix by various methods to develop the mechanical properties of the composites. [10]. These reinforcements significantly enable to increase the hardness and wear resistance values of the metal matrix composites compared with $\mathrm{Al}$ and its alloys [10]. 
$\mathrm{NbB}_{2}$ is a transition metal boride which has widespread high performance applications due to its high melting point, high hardness, good corrosion resistance and other high temperature mechanical properties [11]. $\mathrm{NbB}_{2}$ found application fields in mechanical industry, chemistry and microelectronics [12]. It has been mostly used as refractories, cutting tools, drills, abrasives and wear-resistant pieces [12].

\section{Experimental procedure}

Elemental Al powders (Alfa Aesar ${ }^{\mathrm{TM}}, 99.5 \%$ purity, $12 \mu \mathrm{m}$ ) and Si powders (Alfa Aesar ${ }^{\mathrm{TM}}, 99.99 \%$ purity, $<20 \mu \mathrm{m}$ ) were used as the starting materials in the experiments. $\mathrm{NbB}_{2}$ powders (Alfa Aesar ${ }^{\mathrm{TM}}, 99 \%$ purity, $\leq 44 \mu \mathrm{m}$ ) were added as reinforcement materials in the Al-Si matrix. Al powders, $12.6 \mathrm{wt} \%$ Si powders and $2 \mathrm{wt} \% \mathrm{NbB}_{2}$ powders were blended and mechanically alloyed (MA'd) for 1, 4 and $8 \mathrm{~h}$ in a Spex ${ }^{\mathrm{TM}}$ 8000D Mixer/Mill (1200 rpm) using hardened steel vial/balls with a 7/1 ball-to-powder weight ratio (BPR). Also, 2 wt.\% stearic acid $\left(\mathrm{CH}_{3}\left(\mathrm{CH}_{2}\right)_{16} \mathrm{COOH}\right)$ was added as a process control agent (PCA) to prevent agglomeration and excessive cold welding during the mechanical alloying (MA) process. Milling atmosphere was selected as Ar gas (Linde ${ }^{\mathrm{TM}}$, 99.999\% purity) and sample handling was done in a Plaslabs ${ }^{\mathrm{TM}}$ glovebox. MA'd powders are hereafter referred to as Al-12.6 wt.\% Si-2 wt.\% $\mathrm{NbB}_{2}$ powders. Microstructural and phase characterizations of the powders and sintered samples were carried out using a Jeol ${ }^{\mathrm{TM}}-6000$ Neoscope scanning electron microscope (SEM) and a Bruker ${ }^{\mathrm{TM}} \mathrm{X}$-ray diffractometer (XRD) $\left(\mathrm{CuK}_{\alpha}\right.$ radiation). Average crystallite sizes and lattice strains of the MA'd powders were determined utilizing Bruker-AXS ${ }^{\mathrm{TM}}$ TOPAS V3.0 software. Besides, thermal analysis was performed using a $\mathrm{TA}^{\mathrm{TM}}$ Instruments SDT Q600 differential scanning calorimeter (DSC) to determine the sintering temperature. MA'd powders were compacted in a 10 ton capacity MSETM uni-action hydraulic press with a pressure of 400 $\mathrm{MPa}$ into cylindrical green compacts with a diameter of about $12 \mathrm{~mm}$. PCA was removed from the compacted green bodies by debinding at $420^{\circ} \mathrm{C}$ for $1 \mathrm{~h}$ with a heating and cooling rate of $2^{\circ} \mathrm{C} / \mathrm{min}$ under Ar flow. Samples were sintered at $570^{\circ} \mathrm{C}$ for $2 \mathrm{~h}$ under Ar gas in a Linn ${ }^{\mathrm{TM}} \mathrm{HT}-1800$ high temperature controlled atmosphere furnace with a heating and cooling rate of $5^{\circ} \mathrm{C} / \mathrm{min}$. After the preparation of the composite samples, densities of the samples were determined by using Archimedes method. Hardness measurements were carried out in a Shimadzu ${ }^{\mathrm{TM}}$ Vickers microhardness tester under a load of $100 \mathrm{~g}$ for $10 \mathrm{~s}$, and average results were calculated after 20 successful indentations. Sliding wear tests were carried out using a Tribotech $^{\mathrm{TM}}$ Oscillating Tribotester under $3 \mathrm{~N}$ loading conditions with a sliding speed of $10 \mathrm{~mm} / \mathrm{s}$ and a stroke length of 5 $\mathrm{mm}$ for a total sliding distance of $25000 \mathrm{~mm}$, using a 100Cr6 steel ball ( $\phi 6 \mathrm{~mm}$ diameter).

\section{Results and discussion}

XRD patterns of the as-blended and MA'd (for 1, 4 and 8 h) Al-12.6 wt.\% Si-2 wt.\% NbB 2 powders are given in Fig. 1. Only $\mathrm{Al}, \mathrm{Si}$ and $\mathrm{NbB}_{2}$ phases were observed from the diffraction patterns. Any secondary phase or intermetallic phase was not detected, indicating that any reaction did not take place between $\mathrm{Al}, \mathrm{Si}$ and $\mathrm{NbB}_{2}$ particles or Fe impurity worn from the milling vials/balls. Peak intensities were decreased and peak shapes were broadened with increasing MA time. Crystallite sizes of the particles decreased by increasing MA time (Fig. 2(a)). On the other hand, increasing MA time increases the lattice strain and deformation (Fig. 2(b)).

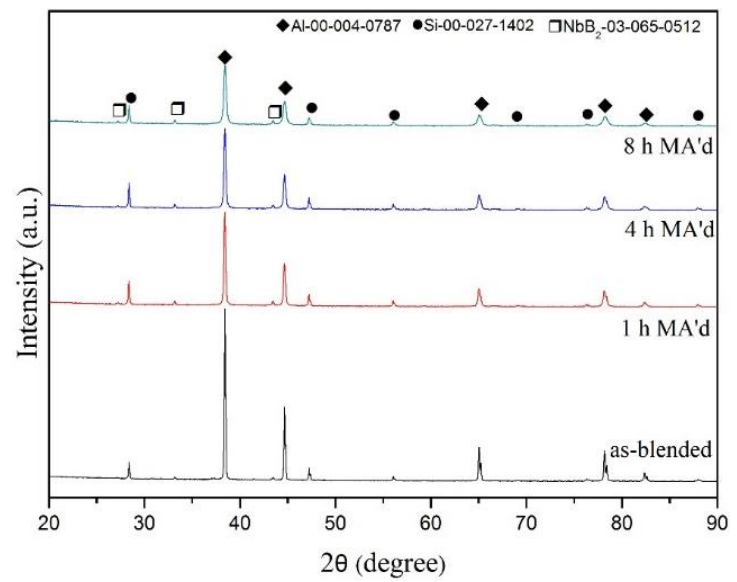

Fig. 1: XRD patterns of the as-blended and MA'd Al-12.6 wt.\% Si-2 wt.\% $\mathrm{NbB}_{2}$ powders at various durations $(1,4$ and $8 \mathrm{~h})$. 


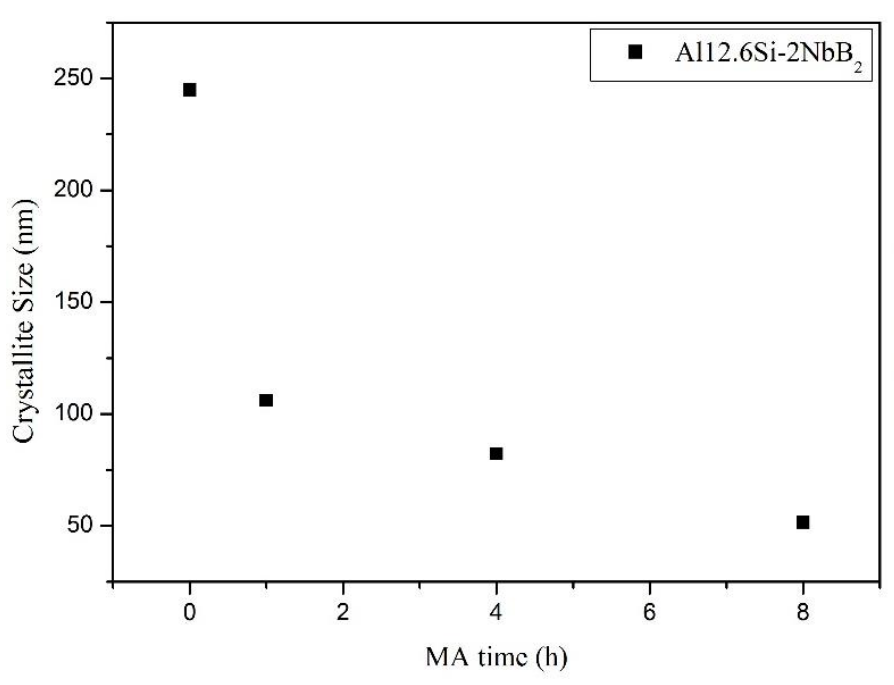

(a)

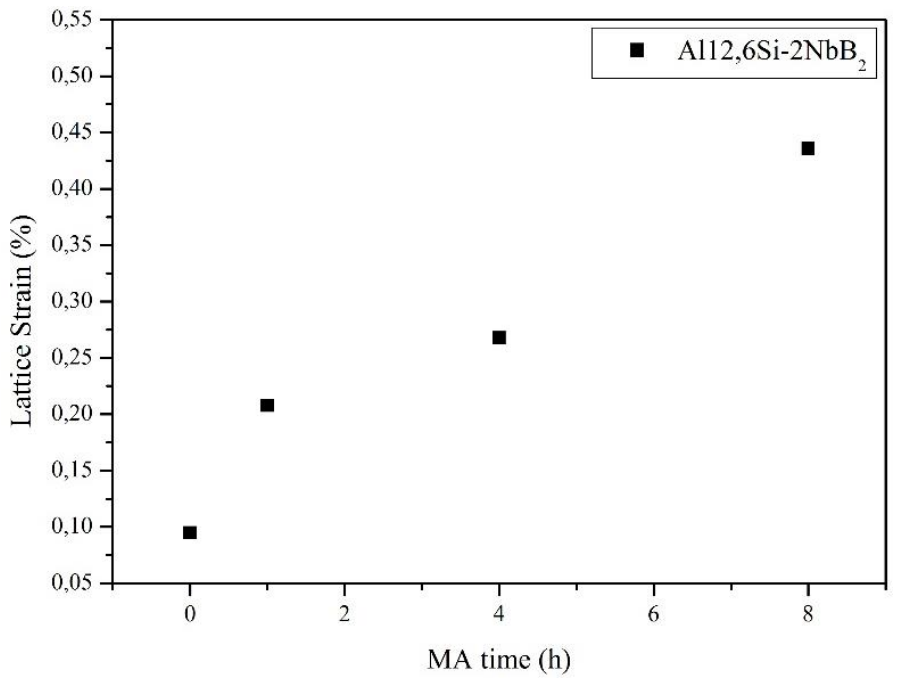

(b)

Fig. 2: (a) Crystalitte sizes of $\mathrm{Al}$ in the as-blended and $\mathrm{MA}$ 'd $\mathrm{Al}-12.6 \mathrm{wt} . \% \mathrm{Si}-2 \mathrm{wt} . \% \mathrm{NbB}_{2}$ powders at various durations $(1,4$ and $8 \mathrm{~h})$ and (b) corresponding lattice strains in the as-blended and MA'd Al-12.6 wt.\% Si-2 wt.\% NbB 2 powders at various durations (1, 4 and $8 \mathrm{~h})$.

Fig. 3 illustrates the SEM images of the as-blended and 1, 4 and $8 \mathrm{~h}$ of MA'd powders. The effect of MA can be obviously observed from the changes of the particle morphologies by increasing milling time. Al and Si particles can be easily seen from the as-blended powders from the Fig. 3(a). Darker and larger particles are the Al particles whereas smaller and brighter particles represent the Si particles. After $1 \mathrm{~h}$ of MA, particles got a flaky morphology (Fig. 3(b)). After MA for 4 and 8 h (Fig. 3(c) and Fig. 3(d)), particles become a more incorporated structure by colliding and welding of them with each other and with milling vial/balls. Due to the ductile character of $\mathrm{Al}, \mathrm{Si}$ and $\mathrm{NbB}_{2}$ particles can be easily embedded into the Al matrix.

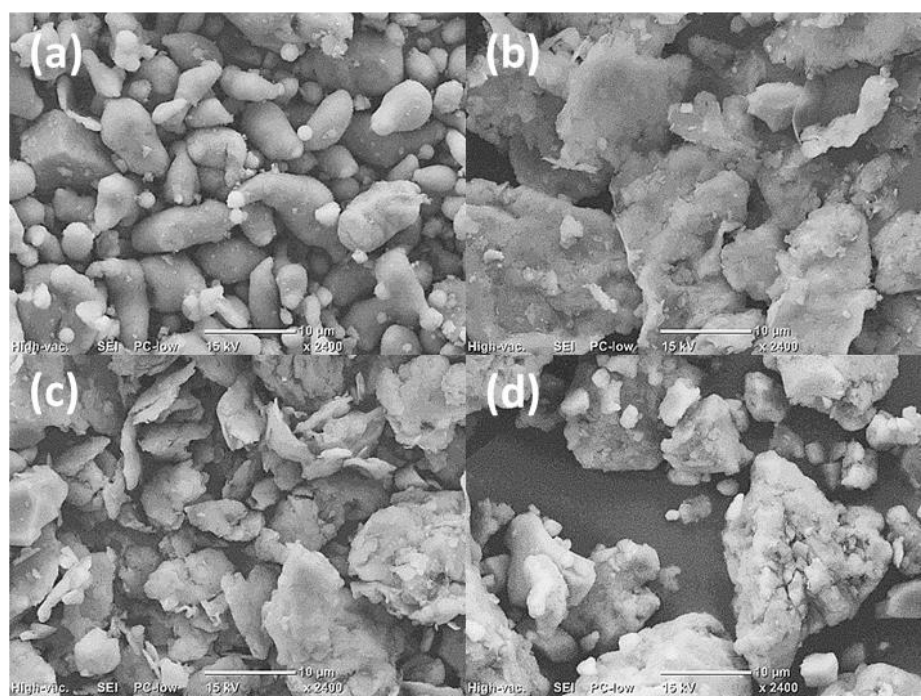

Fig. 3: SEM images of the as-blended and MA'd Al-12.6 wt.\% Si-2 wt.\% $\mathrm{NbB}_{2}$ powders:

(a) as-blended, (b) MA'd for $1 \mathrm{~h}$, (c) MA'd for $4 \mathrm{~h}$ and (d) MA'd for $8 \mathrm{~h}$.

EDX mappings show that $\mathrm{Al}$ and Si particles are isolated from each other in the as-blended powders (Fig. 4(a)). After $4 \mathrm{~h}$ of MA, Si particles are incorporated as seen in Fig. 4(b). Boron element could not be detected by EDX analyses due to its low atomic number. Therefore, only $\mathrm{Nb}$ element was detected during mapping analyses as a proof of the $\mathrm{NbB}_{2}$ phase. $\mathrm{Nb}$ element was uniformly dispersed within the $\mathrm{Al}$ and Si particles in the both as-blended and MA'd powders. 

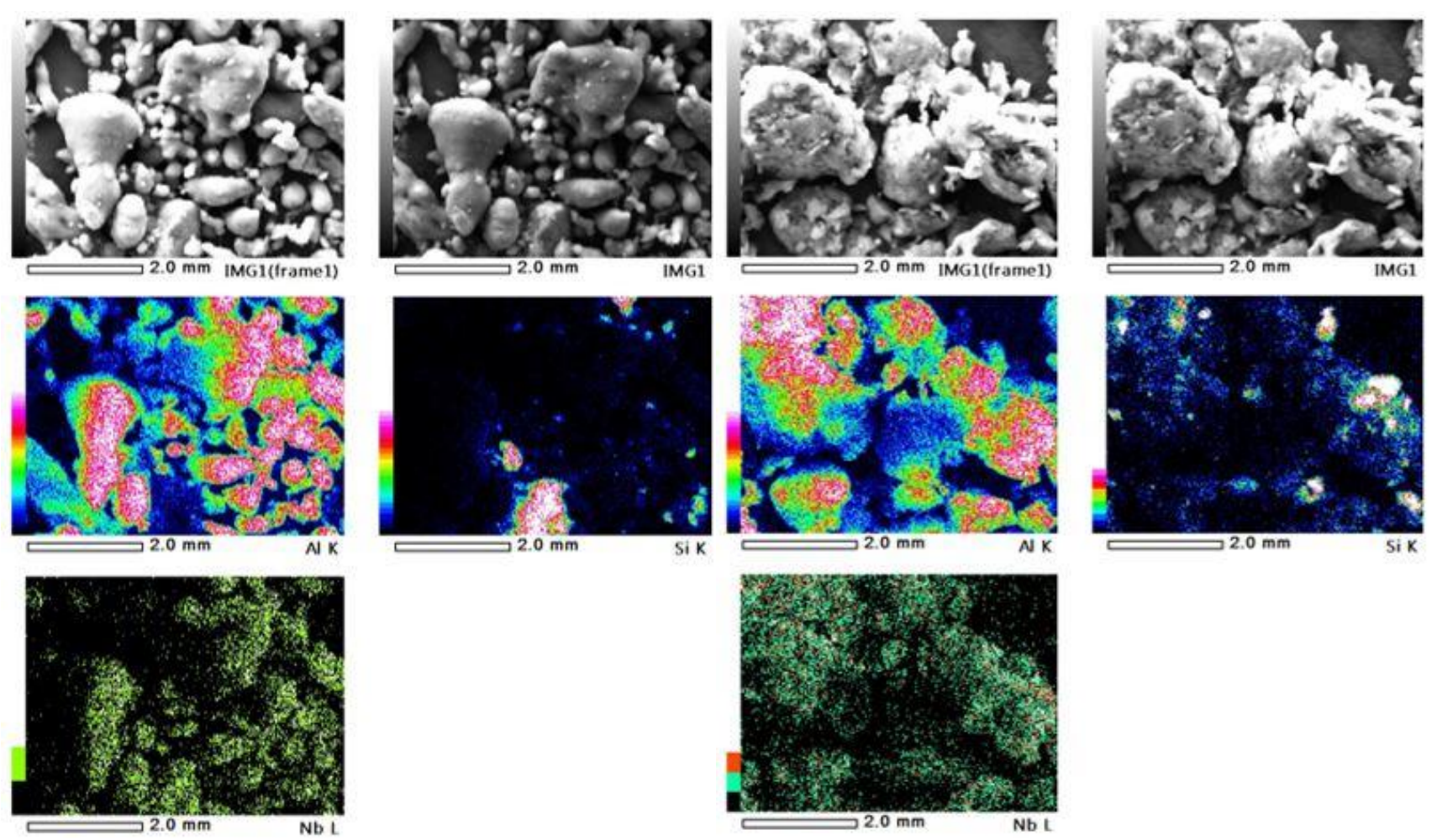

(a)

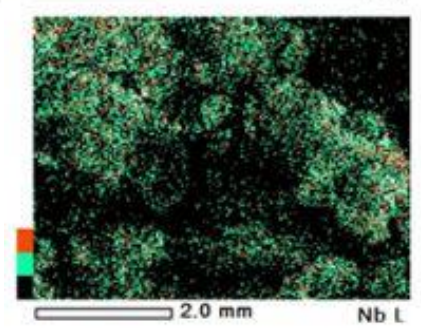

(b)

Fig. 4: Mapping analyses of the as-blended and MA'd Al-12.6 wt.\% Si-2 wt.\% $\mathrm{NbB}_{2}$ powders:

(a) as-blended and (b) MA'd for $4 \mathrm{~h}$.

Thermal analyses were conducted on the as-blended and milled powders (Fig. 5). DTA analyses showed an endothermic peak belonging to as-blended powders nearly at $660.74^{\circ} \mathrm{C}$ which is the melting temperature of aluminium. In a comparison with the as-blended powders, endothermic peak shifted to $581.03^{\circ} \mathrm{C}$ in the $4 \mathrm{~h}$ of MA'd powders, which nearly corresponds to the Al-Si eutectic point. Thermal analyses show that mechanical alloying is occurred. On the basis of these results, the sintering temperature was determined as $570^{\circ} \mathrm{C}$.

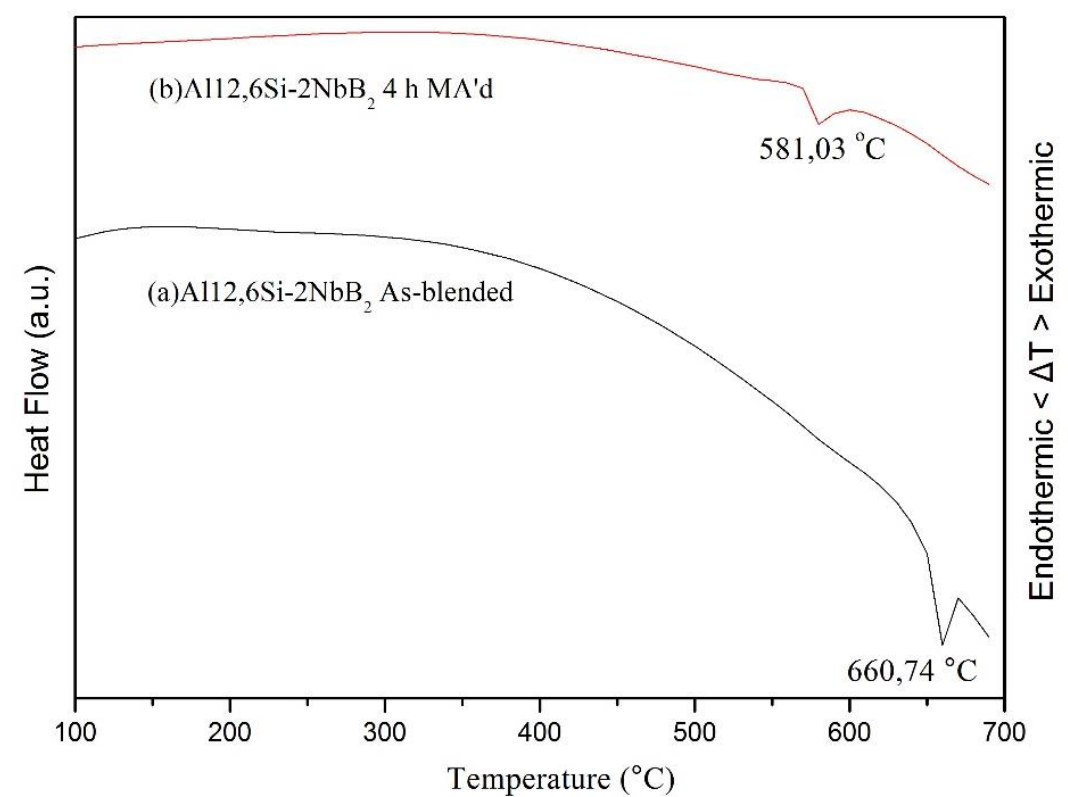

Fig. 5: DSC scans of the as-blended and 4 h of MA'd Al-12.6 wt.\% Si-2 wt.\% $\mathrm{NbB}_{2}$ powders. 
Fig. 6(a) and Fig. 6(b) represent the SEM images of the as-blended and $4 \mathrm{~h}$ of MA'd samples. Fig. 6(a) shows that $\mathrm{Si}$ phases exist at the grain boundaries of $\mathrm{Al}$ matrix. Additionally, porosities can be clearly seen in the sintered Al-12.6 wt. $\%$ $\mathrm{Si}-2$ wt. $\% \mathrm{NbB}_{2}$ samples.

On the other hand, after $4 \mathrm{~h}$ of MA, Si phases are dispersed in the Al matrix homogeneously, as seen in Fig. 6(b). Additionally, porosities can be clearly seen on the as-blended and sintered Al-12.6 wt. $\% \mathrm{Si}-2 \mathrm{wt} . \% \mathrm{NbB}_{2}$ microstructures. It can be said that MA decreases the porosities at the sintered Al-12.6 wt.\% Si-2 wt.\% NbB samples.
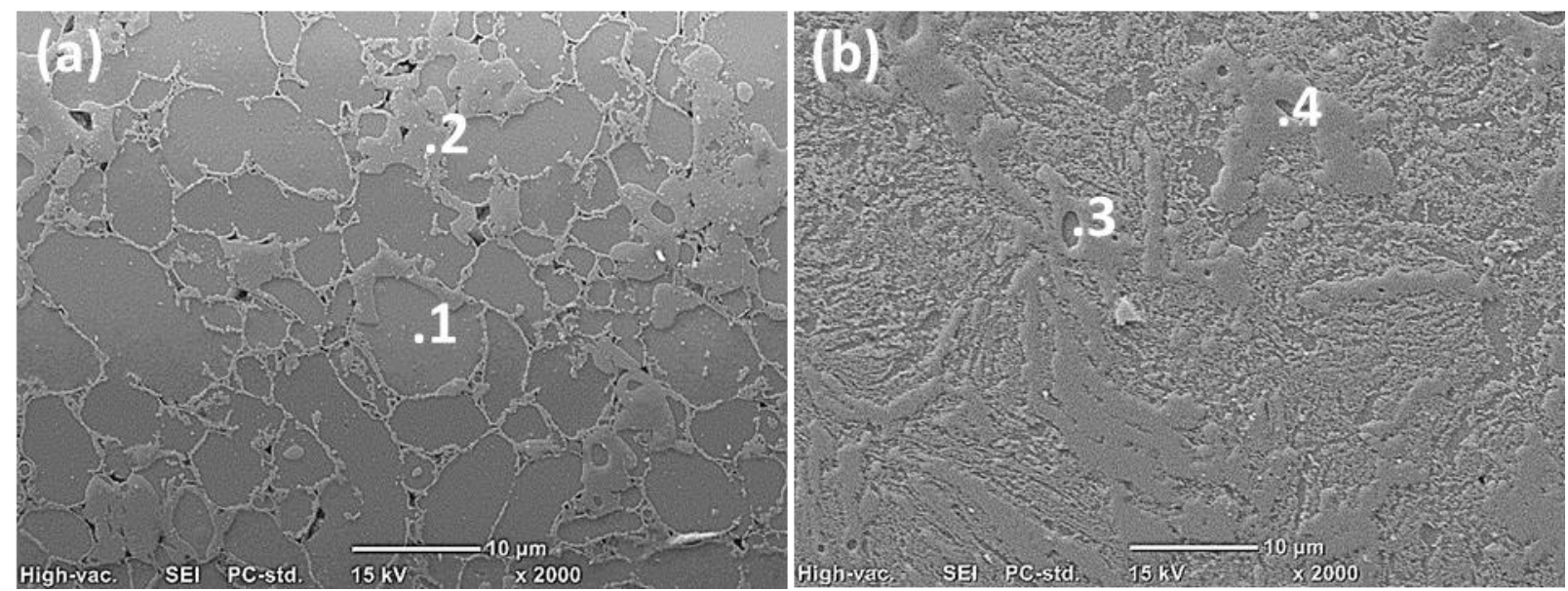

Fig. 6: SEM images of the (a) as-blended and sintered Al-12.6 wt.\% Si-2 wt.\% NbB 2 composite, (b) $4 \mathrm{~h}$ of MA'd and sintered Al-12.6 wt.\% $\mathrm{Si}-2$ wt. $\% \mathrm{NbB}_{2}$ composite.

Table 1 shows the EDX analyses of the marked regions in Fig. 6(a) and Fig. 6(b). According to the Table 1, EDX analyses verify that brighter regions belong to the Si phases and darker regions belong to the $\mathrm{Al}$ phases.

Table 1: EDX analyses of as-blended/4 h of MA'd and sintered Al-12.6 wt.\% Si-2 wt.\% NbB 2 composites.

\begin{tabular}{|c|c|c|}
\hline & Al (wt.\%) & Si (wt.\%) \\
\hline $\mathbf{1}$ & 99.52 & 0.48 \\
\hline $\mathbf{2}$ & 17.31 & 82.69 \\
\hline $\mathbf{3}$ & 99.39 & 0.61 \\
\hline $\mathbf{4}$ & 11.44 & 88.56 \\
\hline
\end{tabular}

Density and hardness values of the as-blended/MA'd and sintered Al-12.6 wt.\% Si-2 wt.\% NbB 2 composites can be seen at Table 2. Relative density values range between 88.06 to $94.25 \%: 4 \mathrm{~h}$ of MA'd and sintered Al-12.6 wt.\% Si-2 wt.\% $\mathrm{NbB}_{2}$ sample has the highest relative density. However, MA has a positive contribution on the density values of the samples. The increase in the microhardness values is clearly seen by increasing MA time. As-blended and sintered Al-12.6 wt.\% Si2 wt. $\% \mathrm{NbB}_{2}$ sample has a hardness value of $55.84 \pm 11.48$. On the other hand, $4 \mathrm{~h}$ of MA'd and sintered Al-12.6 wt.\% Si-2 wt.\% $\mathrm{NbB}_{2}$ exhibits the highest hardness value of $158.50 \pm 10.02$.

Table 2: Density and microhardness values of the as-blended/MA'd and sintered Al-12.6 wt.\% Si-2 wt.\% NbB 2 composites.

\begin{tabular}{|c|c|c|c|c|}
\hline MA duration & $\begin{array}{c}\text { Theoretical } \\
\text { density } \\
\left(\mathrm{g} / \mathrm{cm}^{\mathbf{3}}\right)\end{array}$ & $\begin{array}{c}\text { Archimedes } \\
\text { density } \\
\left(\mathrm{g} / \mathrm{cm}^{\mathbf{3}}\right)\end{array}$ & $\begin{array}{l}\text { Relative density } \\
\qquad\left(\mathrm{g} / \mathrm{cm}^{\mathbf{3}}\right)\end{array}$ & $\begin{array}{c}\text { Vickers } \\
\text { microhardness }\end{array}$ \\
\hline as-blended & \multirow{4}{*}{2.68} & 2.44 & 91.22 & $55.84 \pm 11.48$ \\
\hline $1 \mathrm{~h}$ & & 2.36 & 88.06 & $100.76 \pm 7.75$ \\
\hline $4 \mathrm{~h}$ & & 2.53 & 94.25 & $158.50 \pm 10.02$ \\
\hline $8 \mathrm{~h}$ & & 2.43 & 90.57 & $137.55 \pm 7.92$ \\
\hline
\end{tabular}


Table 3 represents the wear volume losses of the unmilled and sintered Al-12.6 wt.\% Si, $4 \mathrm{~h}$ of MA'd and sintered Al12.6 wt.\% Si, 4 h of MA'd and sintered Al-12.6 wt.\% Si-2 wt.\% NbB 2 . Unmilled and sintered Al-12.6 wt.\% Si sample has a wear volume loss value of $0.511 \mathrm{~mm}^{3} .4 \mathrm{~h}$ of MA'd and sintered Al-12.6 wt.\% Si sample has a wear volume loss value of $0.194 \mathrm{~mm}^{3}$. This means that MA dramatically decreases the wear volume loss. Additionaly, $4 \mathrm{~h}$ of MA'd and sintered Al12.6 wt.\% $\mathrm{Si}-2 \mathrm{wt} . \% \mathrm{NbB}_{2}$ has a wear volume loss value of $0.161 \mathrm{~mm}^{3}$. Thus, it can bee seen that $\mathrm{NbB}_{2}$ addition makes a positive contribution to the wear volume loss.

Table 3: Wear volume loss values of the as-blended/MA'd and sintered Al-12.6 wt.\% Si alloys and $4 \mathrm{~h}$ MA'd and sintered Al-12.6 wt.\% $\mathrm{Si}-2$ wt.\% $\mathrm{NbB}_{2}$ composites.

\begin{tabular}{|c|c|}
\hline Material & $\begin{array}{c}\text { Wear Volume Loss }\left(\mathbf{m m}^{\mathbf{3}}\right) \\
(\mathbf{3 N})\end{array}$ \\
\hline $\mathrm{Al} 12.6 \mathrm{Si}$ As-blended & 0.511 \\
\hline $\mathrm{Al12.6Si} 4 \mathrm{~h} \mathrm{MA}$ 'd & 0.194 \\
\hline $\mathrm{Al} 12.6 \mathrm{Si}-2 \mathrm{NbB}_{2} 4 \mathrm{~h} \mathrm{MA}$ 'd & 0.161 \\
\hline
\end{tabular}

Fig. 7(a)-(c) are the SEM images of the worn surfaces taken from the unmilled and sintered Al-12.6 wt.\% Si, $4 \mathrm{~h} \mathrm{MA}$ 'd and sintered Al-12.6 wt.\% Si, 4 h MA'd and sintered Al-12.6 wt.\% Si-2 wt.\% NbB2. It is clearly seen that, $\mathrm{MA}_{2}$ and $\mathrm{NbB}_{2}$ addition result in a narrower worn surface. Additionally, deep ruptured regions are more remarkable at the $4 \mathrm{~h}$ of MA'd Al12.6 wt.\% Si worn surfaces compared to the $4 \mathrm{~h}$ of $\mathrm{MA}^{\prime} \mathrm{d}$ and $\mathrm{NbB}_{2}$ reinforced Al-12.6 wt.\% Si samples.

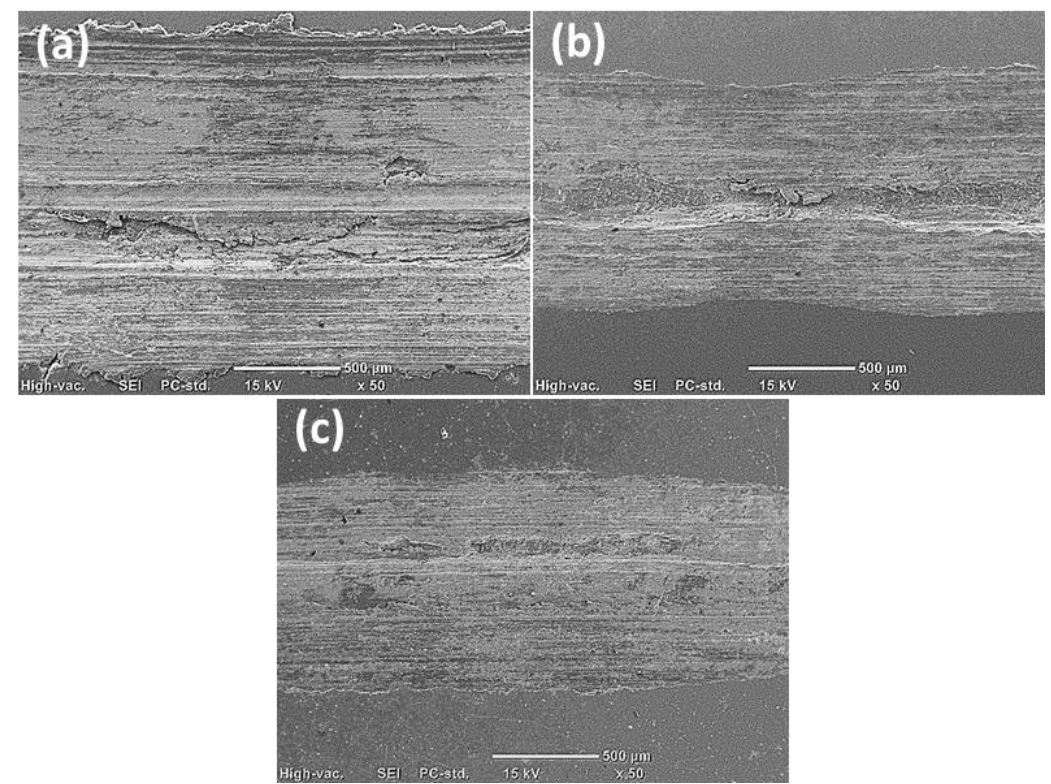

Fig. 7: SEM images of the worn surfaces taken from the (a) as-blended and sintered Al-12.6 wt.\% Si sample (50X), (b) $4 \mathrm{~h}$ of MA'd and sintered Al-12.6 wt.\% Si sample, (c) 4 h of MA'd and sintered Al-12.6 wt. \% Si-2 wt.\% NbB 2 sample.

\section{Conclusion}

Physical, microstructural and some mechanical properties $\mathrm{NbB}_{2}$ reinforced eutectic Al-Si matrix composites were improved by mechanical alloying and pressureless sintering. XRD peaks belong to the particles broadened with increasing MA time due to the increment of lattice strain and decrement of crystallite size. SEM images obtained from powders showed that powder morphology changed to flaky shape to an incorporated structure after $4 \mathrm{~h}$ of MA. Additionally, it was seen by EDX mapping analyses that $\mathrm{Si}$ and $\mathrm{NbB}_{2}$ was homogeneously dispersed in matrix at $4 \mathrm{~h} \mathrm{MA}$ time. Endothermic peak seen from DTA analyses shifted from Al's $\mathrm{T}_{\mathrm{m}}\left(\sim 660.74^{\circ} \mathrm{C}\right)$ to a near-eutectic temperature $\left(581.03^{\circ} \mathrm{C}\right)$ with increasing MA time. $\mathrm{Si}$ was located at the grain boundaries on the as-blended and sintered Al-12.6 wt.\% Si- $2 \mathrm{wt} . \% \mathrm{NbB}_{2}$. On the other hand, SEM 
image and EDX analyses of the $4 \mathrm{~h}$ MA'd and sintered Al-12.6 wt.\% Si-2 wt.\% NbB 2 revealed that, Si phases were dispersed homogeneously in the matrix. This was thought to be the reason of the increment in microhardness and wear resistance by increasing MA time. Amongst all the MA'd samples, 4 h MA'd and sintered Al-12.6 wt.\% Si-2 wt.\% NbB 2 exhibited the highest relative density value of $94.25 \%$ and highest microhardness value of $158.50 \pm 10.02$ and wear volume loss value of $0.161 \mathrm{~mm}^{3}$.

\section{Acknowledgements}

This study was supported by "The Scientific and Technological Research Council of Turkey (TÜBİTAK)" with the project number of 214M093.

\section{References}

[1] J. M. Torralba, C. E. Da Costa, and F. Velasco, "P/M aluminium matrix composites: an overview," Journal of Materials Processing Technology, vol. 133, no. 1-2, pp. 203-206, 2003.

[2] G. Abouelmagd, "Hot deformation and wear resistance of P-M aluminium," Journal of Materials Processing Technology, vol. 155-156, no. 1-3, pp. 1395-1401, 2004.

[3] Y. Nishida, Introduction to Metal Matrix Composites Fabrication and Recycling. Japan: Springer, pp. 1-43, 2013.

[4] T. Rølland, R. Schmidt, L. Arnberg, and W. Thorpe, "Macrosegregation in indirectly squeeze cast Al-0.9wt\%Si," Materials Science and Engineering: A, vol. 212, no. 2, pp. 235-241, 1996.

[5] J. Barrirero, M. Engstler, N. Ghafoor, N. de Jonge, M. Odén, and F. Mücklich, "Comparison of segregations formed in unmodified and Sr-modified Al-Si alloys studied by atom probe tomography and transmission electron microscopy," Journal of Alloys and Compounds, vol. 611, pp. 410-421, 2014.

[6] D. B. Miracle, "Metal matrix composites - From science to technological significance," Composites Science and Technology, vol. 65, no. 15-16, pp. 3-17, 2005.

[7] C. Suryanarayana and N. Aqeeli, "Mechanically alloyed nanocomposites," Progress in Materials Science, vol. 58, no. 4 pp. 383-502, 2013.

[8] C. Suryanarayana, E. Ivanov, and V. V. Boldyrev, "The Science and Technology of Mechanical Alloying," Materials Science and Engineering A, vol. 304-306, pp. 151-158, 2001.

[9] E. J. Lavernia, B. Q. Han, and J. M. Schoenung, "Cryomilled nanostructured materials: Processing and properties," Materials Science and Engineering A, vol. 493, no. 1-2, pp. 207-214, 2008.

[10] Ö. Balcı, D. Ağaoğulları, D. Ovalı, M. L. Öveçoğlu, and İ. Duman, "In situ synthesis of $\mathrm{NbB}_{2}-\mathrm{NbC}$ composite powders by milling-assisted carbothermal reduction of oxide raw materials," Advanced Powder Technology, vol. 26, no. 4, pp. 1200-1209, 2015.

[11] Ö. Balc1, D. Ağaoğulları, H. Gökçe, İ. Duman, and M. L. Öveçoğlu, "Influence of TiB 2 particle size on the microstructure and properties of $\mathrm{Al}$ matrix composites prepared via mechanical alloying and pressureless sintering," Journal of Alloys and Compounds, vol. 586, no. 1, pp. 78-84, 2014.

[12] O. Torabi, S. Naghibi, M. H. Golabgir, H. Tajizadegan, and A. Jamshidi, "Mechanochemical synthesis of $\mathrm{NbC}^{-\mathrm{NbB}_{2}}$ nanocomposite from the $\mathrm{Mg} / \mathrm{B}_{2} \mathrm{O}_{3} / \mathrm{Nb} / \mathrm{C}$ powder mixtures," Ceramics International, vol. 41, no. 41, pp. 5362-5369, 2015. 